\title{
Las asociaciones y los bienes que generan. El debate conceptual y metodológico
}

\section{Associations and social goods. The conceptual and methodological discussion}

doi: http://dx.doi.org/10.32870/

espiral.v25i71.5753

\section{Resumen}

Este artículo discute diversos enfoques sobre los bienes asociativos con el fin de establecer una posición respecto a si los bienes generados mediante la participación e incidencia de los ciudadanos en la vida pública pueden ser identificados como bienes comunes. La argumentación se construye considerando a las asociaciones como espacios institucionales de libre participación que integran un tipo particular de normas y relaciones para el uso de los recursos y los bienes que aquellas generan. El análisis identifica recursos y resultados en la dinámica asociativa, que pueden ser caracterizados como bienes comunes en dos ámbitos: los que son resultado de la pertenencia a los grupos asociativos, y los que generan las asociaciones como resultado de su actuar en la sociedad.

Palabras clave: asociaciones, bienes asociativos, bienes comunes, organizaciones no lucrativas, acción colectiva.
Gloria Jovita Guadarrama Sánchez

\begin{abstract}
This paper examines and discusses some propositions for the conceptualization of associative goods. The purpose is to explore if those goods generated by the participation of citizens can be conceptualized as commons. The argument is supported on the assumption that associations are spaces of free participation built upon a particular kind of rules and relations for the use and distribution of the resources and assets shared. Following this line, the paper identifies the actives that could be characterized as commons in two spheres: those that are shared and generated as result of the integration of members to associative groups, and those generated by associations as result of their actions.
\end{abstract}

Keywords: Associations, associative goods, commons, collective action and nonprofit organisations.

- Profesora-Investigadora de El Colegio Mexiquense, México. ORCID: http://orcid.org/00000003-3726-5646.

ggloriags@prodigy.net.mx

Fecha de recepción: 03 de julio de 2016. Fecha de aceptación: 16 de agosto de 2017. 


\section{Introducción}

Generalmente se acepta que la intervención de asociaciones civiles en la vida pública aporta beneficios a las sociedades que pueden ser estimados como bienes sociales y que son resultado de la acción colectiva. La idea de los bienes como producto de la participación de los ciudadanos en los grupos asociativos abre interrogantes sobre la acción colectiva y sus resultados. Entre dichos interrogantes están los que consideran los tipos de bienes a los que se accede y que se comparten, o bien, que son producidos asociativamente.

El presente análisis explora si en el marco de ese tipo de interacciones es posible identificar al conjunto de relaciones y sus productos y efectos como bienes comunes; se analiza, asimismo, cómo han sido concebidos y caracterizados dichos productos y efectos en distintas perspectivas sobre la acción colectiva.

Conscientes de que la diversidad de asociaciones y de bienes solamente puede ser comprendida desde diversos lentes conceptuales, y que esta discusión únicamente abre espacio para una mirada fragmentada sobre el universo asociativo, abordamos los siguientes puntos: 1) se discute la pertinencia de aplicar una noción particular de bienes comunes a los bienes asociativos (aquellos producidos y compartidos entre miembros de las asociaciones y que son generados por la intervención de asociaciones en la vida pública); 2) se identifican relaciones en el ámbito interno de las asociaciones y de estas con su entorno; 3) se realiza el examen de las relaciones asociativas identificando resultados de acción colectiva que son objeto de apropiación por quienes son miembros o beneficiarios de ellas; y 4) se reflexiona sobre las ventajas y obstáculos del enfoque de los bienes comunes al ser aplicado a los bienes asociativos. A través de esos hilos conductores, convergentes e imbricados entre sí, se intenta discutir el posicionamiento del 
sector asociativo como creador potencial de bienes y explorar la naturaleza, rasgos y atributos de esos bienes para, finalmente, argumentar una posición sobre el papel de las asociaciones en las iniciativas que buscan construir a través de la acción colectiva vías alternativas a la desigualdad y la exclusión.

Antes de proceder a examinar los bienes asociativos, es pertinente incluir algunas premisas sobre las propias asociaciones, implícitas en la intención de explorar sus posibilidades como generadoras de bienes. Este planteamiento surge de una pregunta central sobre la factibilidad de la existencia de asociaciones voluntarias, autónomas, constituidas por ciudadanos libres e iguales, cuya operación esté al margen del Estado y del mercado y que trabajen para un bien común y en consecuencia generen bienes sociales. La interrogante emana tanto de una realidad compleja y de la diversidad del universo asociativo como de las dificultades de abstracción de esa realidad para estructurar algún tipo de líneas o categorías que guíen el análisis.

Con relación a esos dilemas, se puede decir que la noción de las asociaciones como un sector generador de bienestar al margen del Estado y del mercado constituye toda una corriente de pensamiento que ha venido desarrollándose en las últimas décadas a partir de la presencia creciente de organizaciones sociales cuyas estructura y formas de operación inciden en los procesos de acceso, distribución y uso de los bienes que requiere el funcionamiento de las sociedades, pero que no se corresponden con los objetivos, motivaciones y mecanismos de control predominantes en la economía de mercado ni con los fines del Estado respecto a su intervención en la generación de bienestar (Esping Andersen, 1990 y 1999; Laville, 2015). En ese conjunto de asociaciones, se encuentran las empresas sociales, el comercio justo, los servicios de proximidad, los bancos comunitarios y otras formas solidarias identificadas como 
organizaciones civiles, entre las cuales se incluyen distintas formas asociativas que se particularizan por su carácter de afiliación voluntaria y que se consideran autónomas para plantear sus fines, estructura y funcionamiento.

Se infiere de lo expuesto que las asociaciones, tal como se conciben en este texto, son parte del conjunto de organizaciones emergentes a través de las cuales la sociedad civil busca responder a las debilidades e insuficiencias del Estado para enfrentar los problemas sociales y disminuir los constreñimientos excluyentes para la procuración del bienestar que impone la economía de mercado. En ese sentido, la concepción de las asociaciones como ámbitos de acción colectiva y generadoras de bienes es en buena medida una abstracción que permite examinarlas como un sector con ciertos rasgos y atribuciones que son justificados por el marco teórico y la argumentación que articula el análisis. ${ }^{1}$

\section{Las asociaciones civiles y el interés colectivo}

Existen diversos conceptos sobre la naturaleza de las formas asociativas y sobre su intervención en la vida pública. Walzer (1991) considera que la sociedad civil es la esfera de asociación humana no coercitiva y el conjunto de redes relacionales formadas para el beneficio e interés de la sociabilidad misma, esfera que llena el espacio entre el individuo y el Estado y en la que es posible emprender accio-

I.Las asociaciones libres, voluntarias, autónomas, con fines solidarios y mecanismos no lucrativos constituyen un tipo ideal que no necesariamente se corresponde con la realidad del universo asociativo. En esa realidad compleja, numerosas asociaciones utilizan mecanismos de mercado y obtienen ganancias que justifican en función de sus fines, funcionan también como complementarias en las responsabilidades del Estado para la procuración del bienestar y son subsidiadas por los Gobiernos, lo que no invalida el papel de las asociaciones en la economía del bienestar. El análisis y la argumentación que se proponen en el presente texto utilizan selectivamente esos rasgos para posicionar sus potencialidades en la generación de bienes y examinan la pertinencia de considerar algunos de ellos como comunes. 
nes colectivas para propósitos normativos o sustantivos, relativamente independientes del Gobierno y del mercado.

Jeffrey Alexander (2006), por su parte, circunscribe el universo asociativo a una esfera civil solidaria que privilegia el interés colectivo. En su opinión, no todas las formas asociativas pueden ser inscritas bajo el rubro de asociaciones civiles: esta esfera se identifica no sólo por su carácter voluntario, sino por su compromiso cívico y su orientación hacia el interés público. Así, las asociaciones civiles son concebidas como voluntarias y autónomas, integradas por ciudadanos al margen del poder coercitivo del Estado y del mercado y, en consecuencia, capaces de contribuir al bienestar colectivo.

Estas perspectivas, entonces, caracterizan a las asociaciones como agrupaciones que intervienen el espacio público para resolver problemas y atender necesidades sociales, lo cual lleva implícito que tengan la posibilidad de generar bienes.

Desde otros ángulos, Laville (2015) ve el asociacionismo como el conjunto de proyectos constituidos por ciudadanos libres e iguales a partir de acciones colectivas y en aras de un bien común, destacando sus potencialidades para constituir espacios públicos autónomos y para construir una solidaridad democrática. Dichas acciones colectivas no responden únicamente a la perspectiva de obtención de ganancias para sus miembros, sino a su pertinencia para el bien común. En el mismo sentido, Chanial y Laville (2013) señalan que las asociaciones traducen en actos la solidaridad porque están referidas a un bien común y se constituyen como espacios de encuentro entre las redes de sociabilidad primaria y secundaria y las esferas privada y pública.

Si bien las primeras posiciones ubican a las asociaciones como organizaciones privadas no lucrativas dentro de una sociedad que privilegia los mercados y les confieren un rol complementario en la procuración de bienes, en el marco 
de la economía solidaria se les atribuyen potencialidades transformadoras del sistema y de las relaciones económicas a partir de sus acciones para la generación de bienes colectivos. En estas proposiciones conceptuales, muy distintas en sus orígenes, es observable que subyacen concepciones ideológicas y proyectos políticos diferentes. Como lo hace notar Estivill (2015), la concepción del sector asociativo como un tercer sector que ubica las asociaciones al margen del Estado y del mercado está implícita en la visión de su papel compensatorio ante las insuficiencias y fracasos del paradigma de desarrollo neoliberal y es una noción ligada a la tradición filantrópica anglosajona que intenta cubrir las fallas y fracasos del mercado y del Estado.

A su vez, la noción de la economía social, con raíces en Europa, destaca el carácter cooperativo de las asociaciones y les confiere un papel en la construcción de una economía alternativa. Esas distinciones sustentan la idea de que en los conceptos y categorías que permean los estudios sobre las asociaciones pueden estar presentes posiciones ideológicas distintas y hasta opuestas. ${ }^{2}$

Para los fines del presente análisis, se parte de la consideración de que ambas vertientes comparten algunos conceptos y convergen en la idea central de que, cualesquiera que sean sus fines, las perspectivas sobre las asociaciones derivan en verlas como generadoras de bienes.

Debe notarse que los estudios sobre el origen y los propósitos de esas relaciones y la realidad de la heterogeneidad asociativa no siempre coinciden con esa visión abstracta e

2. Las distinciones entre las dos perspectivas son señaladas por Estivill (2015), quien advierte que existen numerosas investigaciones sobre el tercer sector que han identificado a las organizaciones no lucrativas y medido su contribución al empleo y al producto interno bruto; el autor señala entre los autores de dichas investigaciones a Salamon y Anheier. Por otra parte, indica que la economía social tiene su origen en las cooperativas y mutualidades, y ubica entre sus autores relevantes a Laville, en Europa, y a Pablo Guerra y Coraggio, en América Latina (Estivill, 2015, p. 16). 
idealizada de las asociaciones, las cuales también son percibidas como ámbitos excluyentes que privilegian intereses propios y como medios para generar ganancias, es decir, conciben que su acción se encuentra lejos de buscar el bien común. Así, se puede considerar, como lo hace Michael Edwards (2008), que muchas asociaciones filantrópicas, empresas sociales y organizaciones de emprendedores asumen posiciones o medios que extienden el mercado a las causas sociales, privilegian los negocios, venden bienes y servicios, promueven la competitividad y no la cooperación, rechazan compartir, utilizan los lazos asociativos para conformar ámbitos excluyentes y están orientadas a considerar la ganancia y los negocios como el medio para resolver los problemas sociales, o son la puerta de entrada a los clubes de élite y los grupos de prestigio. A su vez, puesta la mirada en esos grupos, Alexander (2006) considera que no cabe considerarlos dentro del tipo de asociaciones civiles, las cuales son identificadas por su orientación hacia una solidaridad sustentada en la ética, la democracia y los derechos. ${ }^{3}$

Para profundizar en la acción y resultados de los grupos asociativos, se puede comenzar por señalar que es posible, dada la complejidad de la sociedad civil, poner la mirada, como lo propone Michael Edwards (2011), no en la diversidad de las formas e identidades asociativas, sino en la forma como interactúan entre ellas y con las instituciones del Estado y del mercado, enfoque que posibilita verlas como ensambles, ecologías o ecosistemas que varían en

3. De acuerdo con Alexander (2006), no es el mero hecho de asociarse el que define a un grupo como civil, sino lo que es asociado con él y el conjunto de otros factores que orientan a la asociación a comprometerse con el entorno civil solidario que existe fuera de ellas. El mismo autor advierte sobre la existencia de asociaciones no-civiles o anticiviles, es decir, que promueven solidaridades anticiviles. Asimismo, citando a Putnam, señala la necesidad de tomar en cuenta que muchas organizaciones sociales y políticas son desafortunadamente propensas a la corrupción (Alexander, 2006). En contraposición, la esfera civil solidaria estaría asociada a los valores democráticos, la ética y la justicia. 
sus características de un contexto a otro: "como en un real ecosistema biológico, cada elemento está relacionado con los otros y obtiene fuerza de la diversidad orgánica y del crecimiento del sistema, así todos los miembros de la sociedad pueden activar sus intereses e intenciones a través de la vida asociativa" (Edwards, 2011, p. 314). Entonces, si las asociaciones mismas pueden considerarse como ecosistemas, los recursos e intercambios que se producen en esa esfera podrían ser vistos como mecanismos de soporte y, al mismo tiempo, estar circunscritos a ámbitos particulares propios de cada lugar y momento histórico.

Sin embargo, para intentar entender cómo se teje la trama de los recursos que se comparten, es necesario efectuar algún tipo de abstracción en el cual puedan ser reconocidas y examinadas. Mark Warren (2009), por ejemplo, define a las asociaciones como grupos de personas que persiguen propósitos comunes mediante cursos de acción cooperativa que se extienden más allá de un acto aislado, y vincula sus cursos de acción con efectos que inciden en el funcionamiento de las sociedades democráticas. Por su parte, Laville (2015) les atribuye la posibilidad de constituir una dimensión económica y democrática a partir de la cual las asociaciones serían la matriz generadora de una economía alternativa, social y solidaria; se les considera incluso como formas de acción colectiva que son a la vez socioeconómicas y sociopolíticas. En ese contexto, la idea de que constituyen ámbitos de afiliación voluntaria y de acción colectiva orientada hacia metas comunes permite ubicar la discusión sobre las interacciones y los bienes en la esfera asociativa.

\section{Asociaciones civiles y bienes}

A partir del presupuesto de que las personas participan en las asociaciones para lograr, juntas, objetivos que de otro 
modo serían difíciles de conseguir, y de que en esos empeños se generan o comparten bienes, es posible percibir a las relaciones asociativas como un conjunto de compromisos y acciones colectivas.

En ello está implícito que las acciones generan beneficios para los que participan y que hay un conocimiento común y compartido de cuáles son esos beneficios. Por esas razones, en el trazo de las relaciones asociativas resalta que la participación de los individuos va más allá de la simple coordinación de esfuerzos, porque se arraiga en el interés y el compromiso de alcanzar objetivos comunes y beneficios compartidos, lo que involucra la consecución de los propios intereses por los miembros del grupo que participan de la acción. La participación se establece y se fortalece con los intercambios positivos y está enmarcada en las posibilidades de acceso a recursos y en las expectativas de anudar los esfuerzos de los grupos e individuos participantes en la consecución de beneficios comunes.

En buena medida, la interdependencia determina la necesidad de ser parte de una asociación para acceder a los recursos y bienes que constituyen la esfera solidaria. Ese tejido complejo de motivaciones e intereses puede también ser explicado por la naturaleza particular de la economía de bienes y servicios en la que se inserta su intervención y por la naturaleza específica de los bienes y servicios que producen las asociaciones, la que a su vez se encuentra ligada a criterios que la denominación de no lucrativos determina para quienes los producen o consumen; muchas veces, tal determinación tiene repercusión en los costos de las transacciones y obstaculiza o beneficia los intercambios económicos (Laville, Young y Eynaud, 2015).

En ese marco, la necesidad de considerar diferentes perspectivas para el análisis de los bienes asociativos sugiere ampliar la visión sobre las asociaciones para entender cómo se involucran los miembros y beneficiarios en la gestión de 
los bienes, ya que se estima que las asociaciones pueden detentar formas atípicas de propiedad y gestión, derivadas de la multiplicidad de intereses que pueden conjugar y de la naturaleza cuasicolectiva de los bienes que pueden compartir y proveer (Nyssens y Petrella, 2015).

\section{Bienes comunes}

Una corriente nueva en este campo es la que explora los arreglos que emergen cuando los involucrados (depositarios de activos, inversores, donadores, voluntarios) interactúan en torno al control y la gobernanza de bienes colectivos.

Esta vertiente sigue el trabajo pionero de Ostrom (1992), que rechaza la dicotomía entre el Estado y el mercado, aplicando el concepto de bienes comunes (commons) para examinar cómo los involucrados en la gestión de recursos de uso común pueden auto-organizarse, definir sus propias reglas y actuar colectivamente. Ya que la literatura sobre los comunes es compleja y diversa, para comenzar la discusión proponemos distinguir el término bien común del de bienes comunes.

El término bien común hace referencia a todo bien que está destinado para más de una persona, o al bien que es común a todos. Argandoña (1998) mantiene la idea de que el bien común implica intercambio y reciprocidad, es decir, no solamente la suma de intereses personales, sino también el hecho de compartir entre los miembros y la sociedad (incluso pequeñas asociaciones de individuos) los recursos que resultan de su cooperación. Se aporta y se recibe (aunque probablemente no en la misma medida en que se contribuye). El bien común no es un bien que los individuos hacen a la colectividad o para otras personas, puesto que ellos mismos tienen una participación en ella; se trata de un bien dado y recibido por cada persona (Argandoña, 1998). 
En relación con este punto, cabe referirse al vínculo entre lo que se considera bien común y el interés público, ya que ese vínculo agrega una dimensión positiva a los intercambios cooperativos, que no pueden entonces ser reducidos a lo mercantil. En ese sentido, el bien común puede entenderse como un bien social y como un patrimonio colectivo. Las asociaciones son entonces percibidas como ámbitos de solidaridad y autogobierno en los que sería posible generar respuestas cooperativas para el bien común. Chanial y Laville (2013) advierten, no obstante, que la adhesión a un bien común no es suficiente para la conformación de una acción duradera, pues esta debe sustentarse en acuerdos sobre principios de justificación que integren reglas sobre las relaciones entre usuarios y miembros y sobre la movilización de los recursos.

En cuanto a los bienes comunes (o los comunes), en sus distintas acepciones se incluye la idea de que son recursos materiales o inmateriales de acceso libre a todos o a grupos de personas, pero que no son propiedad exclusiva de ninguna persona en particular, de lo cual deriva la aplicación primera del término a los recursos naturales como el mar, el aire, los bosques, los recursos pesqueros, los pastos, etc. A pesar de la permanencia de esa idea central, la percepción social sobre los comunes ha cambiado en el tiempo, y actualmente su conceptualización contempla sistemas naturales y sociales cuya propiedad y acceso son compartidos colectivamente, e incluye la gestión colectiva de recursos estratégicos para el bienestar de grupos y comunidades.

Así, las nociones sobre los bienes comunes han dado paso a nuevas formas de mirar hacia lo que es o debiera ser compartido, así como a nuevas formas de pensar la procuración del bienestar, cómo puede o debe ser atendido y a quién o a quiénes debe encomendarse su provisión; igualmente, se considera que en la medida que se amplíe, rescate o preserve lo que se considera común, se puede avanzar en construir 
a través de la cooperación un planeta más incluyente. En esa línea de cambio resulta posible considerar que las asociaciones pueden constituirse como ámbitos continentes de generación, disposición y uso de comunes.

Las aportaciones de Charlotte Hess (2008) son pertinentes para esta discusión, ya que la autora aborda el tema de los bienes comunes desde una perspectiva más abierta, llamada new commons (nuevos comunes), en la que el adjetivo nuevo tiene dos significados: 1) como contraste con lo ya establecido (bienes tradicionales), puesto que algunos bienes son de reciente creación a través de las nuevas tecnologías (bienes digitales); 2) como un adjetivo trascendente sobre la conciencia de los bienes comunes, es decir, "Lo nuevo evoca una sensación de despertar, de la recuperación de recursos cruciales perdidos o en amenaza de peligro" (Hess, 2008, p. 74). Su proposición conceptual forma parte de una corriente de pensamiento que se integra como un movimiento de acción colectiva hacia la extensión, retorno y recuperación de los comunes (Coriat, 2015; Grouiez, 2015; Hardt y Negri, 2009; Nonini, 2006), y que se ha extendido en el planeta como una alternativa para enfrentar los desafíos excluyentes de la economía de mercado. ${ }^{4}$

La orientación central de estas perspectivas se traduce en una mirada que busca capturar las facetas de un mundo emergente que traza nuevas significaciones de lo común (Ostrom, 1992; Bollier, 2011; Bollier y Helfrich, 2012; Coriat, 2015) con un sentido en el cual los comunes no se reducen entonces a los objetos o recursos naturales o materiales, sino que está imbuido en ellos el conjunto de prácticas, normas y valores que se combinan para generarlos.

4. De acuerdo con Coriat (20I5), desde el año 2000 se observa un movimiento de retorno a los comunes que se acompaña del surgimiento de estudios que extienden la reflexión sobre los comunes materiales, iniciada por Ostrom, a las formas de comunes inmateriales. La ampliación de los comunes se extiende a los dominios del universo digital, de la creatividad literaria y artística, y del acceso al conocimiento.

\section{0}


En el mismo sentido, pueden ser pensados como bienes que son gestionados de manera diferente a la propiedad privada, ya que combinan modos diversos de compartir la propiedad y el control de los recursos. ${ }^{5}$ Se advierte incluso (Orsi, 2013) que los comunes se construyen a partir de nuevas concepciones de la propiedad en las que esta deja de ser un derecho individual para convertirse en una función social. En el trazo de un perfil sobre la naturaleza de los comunes, Bollier (2011) señala que un común es un recurso al que se suman o integran una comunidad y un conjunto de reglas.

Es importante recuperar aquí el debate en relación con las posibilidades de que grupos y personas puedan acceder y compartir cooperativamente los recursos comunes. La discusión se origina a partir de la posición de Hardin (1968), referida a la degradación y sobreexplotación de los recursos de uso común, cuando los usuarios de los mismos no son capaces de administrarlos ni tienen en cuenta las consecuencias de sus acciones en otros usuarios. La tragedia deriva del libre acceso y de la ausencia de reglas de restricción al uso de los recursos, o bien, cuando las demandas son mayores que su disponibilidad. Ante esos escenarios, las vías posibles para evitar el agotamiento de los bienes son la privatización y la intervención de una autoridad externa. Frente a esa posición, otros estudios consideran que la privatización y el control del Estado no son formas adecuadas de regular el uso de los recursos comunes, pues las consecuencias que derivan de ellas provocan el desman-

5. En esa corriente, destacan las propuestas de Hardt y Negri (2009), que consideran que las amenazas de la privatización, la degradación del entorno y los agudos y extendidos problemas del mundo contemporáneo solamente pueden ser enfrentados a través de compartir y participar en la creación y preservación de lo común. Los comunes no son solamente los recursos naturales: son también los resultados de la producción social necesarios para la interacción social, tales como conocimientos, lenguajes, códigos, información y prácticas de cuidado y cohabitación que limitan el deterioro de lo común. 
telamiento de los entornos ecológicos, sociales y culturales que pueden constituirse como recursos de uso común.

En ese lado de la polémica, destaca Elinor Ostrom (1992), quien argumenta que la tragedia es evitable si se cuenta con formas adecuadas de regular los recursos comunes a través de normas y reglas formales de control y uso sustentable. Desde su óptica, resulta fundamental el estudio de las instituciones de acción colectiva que regulan el establecimiento de derechos de propiedad y de acceso. En su obra Governing the commons: The evolution of institutions for collective action, Ostrom analiza la forma en que los individuos enfrentan distintos tipos de problemas públicos, lo que la lleva a particularizar los bienes que un grupo, comunidad o sociedad utiliza en común, es decir, ningún individuo tiene control exclusivo sobre el uso y disposición de los bienes que pueden ser usados por o estar a disposición de un grupo, comunidad o sociedad, estableciéndose un conjunto de reglas para regularlos con efectividad.

Ostrom (2014) se aparta de la clasificación clásica de bienes, ${ }^{6}$ orientándose a las aportaciones de Buchanan, quien agregó un tercer tipo de bienes, los club goods, con los que reconoció que grupos de individuos crean asociaciones privadas para proveerse a sí mismos de bienes y servicios no rivales a pequeña escala (Ostrom, 2014, p. 20). Ostrom propone entonces reemplazar el adjetivo de club por toll, es decir, bienes de cuota-dentro de los cuales pueden ubicarse espacios comunes como los teatros, clubes privados, guarderías y otros-, puesto que advierte que muchos bienes que son provistos por asociaciones públicas y privadas de pequeña escala comparten características similares. Un

6. Según la clasificación clásica de los bienes, estos pueden ser divididos en: I) los bienes privados, excluibles (su acceso es limitado a quienes los poseen o pagan por su consumo) y rivales (lo consumido ya no puede consumirse por otros); y 2) los bienes públicos, no excluibles (se consumen sin pagar necesariamente algo a cambio) y no rivales (lo consumido por uno no limita el consumo de todos).

\section{2}


punto clave de la posición de Ostrom es su propuesta de ampliar la dicotomía clásica de bienes privados o públicos para incluir otros tipos de bienes; la idea es que existen nuevos tipos y subtipos de bienes que comparten el atributo de la sustractibilidad de uso de los bienes privados, pero con la dificultad de exclusión de los bienes públicos (Ostrom, 2014).

Marthe Nyssens y Francesca Petrella (2015) ubican en este sector productor de bienes a las organizaciones sociales (organizaciones económicas, sociales y solidarias -SSE-) que desarrollan una producción cuasicolectiva de bienes y servicios: economía social, economía solidaria, empresas sociales, organizaciones no lucrativas y asociaciones económicas civiles. En ese terreno, las autoras argumentan que los bienes y servicios provistos por los grupos solidarios no son bienes públicos puros ni bienes privados en su sentido clásico, sino bienes que tienen una dimensión colectiva y en los que también está imbuida una concepción de interés público. Señalan, asimismo, que las organizaciones no son dueñas y que los bienes tampoco son propiedad de los miembros que las conforman, sino que estos se convierten en gestores del patrimonio colectivo. La esencia de las organizaciones solidarias está en generar un bien o servicio para sus miembros o para la comunidad, más que en generar ganancias y en la primacía de la gente sobre el capital.

Otro argumento que permite ligar la visión de Ostrom sobre los comunes a los bienes asociativos estriba en que la autora considera que los derechos de propiedad de los recursos son conformados por conjuntos distintos de derechos: derechos de acceso, derechos de apropiación de los productos, derechos de gestión o administración y derechos de transferencia. Esos conjuntos son separables y se combinan de diferentes maneras en los distintos regímenes de propiedad; la condición de separabilidad permite que los bienes asociativos puedan combinar de manera distinta sus 
particularidades, conformando tipos distintivos en la gestión de bienes y activos por las organizaciones económicas de tipo solidario (Nyssens y Petrella, 2015). Así, derivado de la visión de Ostrom, otros autores señalan que los derechos de propiedad pueden extenderse en formas diferentes hacia los conjuntos de derechos socialmente construidos (Gutwirth y Stengers, 2016; Orsi, 2013). ${ }^{7}$

Un punto más en el reconocimiento de los bienes comunes en Ostrom (2014) es su propuesta de que la complejidad de los recursos a nivel local requiere de sistemas complejos de gobernanza que involucren la contribución ciudadana de distintas formas. Desde su perspectiva, los actores locales son capaces de auto-organizarse para administrar sus recursos comunes, estableciendo sus propios sistemas de reglas. Los bienes asociativos podrían entonces ser considerados como comunes no solamente por sus características propias, sino porque su administración es gobernada por reglas colectivas. Esta proposición abrió también el espacio para el reconocimiento de la diversidad institucional y de la capacidad de las organizaciones para crear formas de intercambio económico distintas a las normas que rigen el mercado.

Aligica (2016) advierte que lo voluntario se vuelve central en su trabajo último sobre la gestión de los recursos de base comunitaria, lo que apunta a la acción voluntaria como la posibilidad de una tercera vía - ni Estado ni mercado-, y como la esfera donde los apropiadores pueden establecer arreglos de gobernanza que permitan un uso más eficiente de los recursos y mejores resultados para todos. ${ }^{8}$ Se puede decir

7. A partir de la visión de Ostrom, Gutwirth y Stengers (2016) señalan la necesidad de que se construyan derechos específicos sobre la propiedad de los comunes, y advierten el papel y la responsabilidad del Estado para que se construyan y salvaguarden esos derechos.

8. No obstante que Ostrom no aborda directamente el ámbito de lo no-lucrativo, las líneas de su trabajo sobre los bienes comunes se estiman convergentes con la forma en la que las organizaciones producen y gestionan una variedad de bienes colectivos (Aligica, 2016).

\section{4}


que, esencialmente, el término bienes comunes se vincula al sentido de comunidad considerando aquellos que tienen relación con un grupo de personas que los considera como propios. Las comunidades se construyen y organizan como formas de integración social que permanecen usando de diferente manera dos dimensiones vitales: el tiempo y el espacio, es decir, pueden constituirse a distancia, trascender el espacio local, organizarse en redes. Un ejemplo de ello son las comunidades virtuales, entre cuyos bienes comunes pueden pensarse el internet y el conocimiento (Helfrich, 2008). Es bajo esas premisas que algunas asociaciones y los bienes que producen pueden llegar a jugar el papel de comunalizadoras, en la medida que abren posibilidades de creación y acceso a los comunes. ${ }^{9}$

Esa visión resulta pertinente para una aproximación a las relaciones de intercambio y bienes en la esfera asociativa, porque los inversores no son los dueños y porque en las asociaciones convergen diferentes tipos de interesados que pueden tomar decisiones sobre sus activos (sus beneficiarios directos, los donantes, los empleados, los directivos, los voluntarios); no obstante, ellos no tienen el derecho de apropiarse de los excedentes o de las ganancias por los servicios o bienes que se proveen y, por lo tanto, se requiere de reglas acordadas que posibiliten la sustentabilidad de las organizaciones.

Entre la diversidad de los nuevos comunes están las bibliotecas, las revistas, los libros y documentos de investi-

9. La denominación de comunalizadoras es una traducción libre del término commoning, utilizado, entre otros, por Bollier y Helfrich (2012) para referirse a las potencialidades $y$ acciones de las organizaciones para impulsar una reapropiación de los comunes, o bien, una generación de nuevos comunes. De acuerdo con lo que señalan Gutwirth y Stengers (2016, p. 323), esto se refiere a un hacer o volver comunes los recursos "no commons with out commoning". Otra acepción del término refiere a los movimientos de resistencia a la privatización y a la mercantilización extensiva de los espacios públicos y a un modo diferente de organización de la sociedad para la preservación de sus bienes (Bollier y Helfrich, 20I2). 
gación de acceso abierto, el software libre, las plataformas ecodigitales, Wikipedia y otros modelos y prototipos de la economía colaborativa, pero también las asociaciones que promueven el comercio justo, los bancos comunitarios, los servicios de proximidad y las cooperativas. En el caso de las asociaciones, Hess (2008) sostiene que existen los bienes culturales, dentro de los cuales se incluye a asociaciones de voluntarios pertenecientes al sector no lucrativo, o bien, a las asociaciones civiles filantrópicas; señala que situarlas en este espacio de reflexión resulta enriquecedor para su estudio y permite comprender mejor su naturaleza (Hess, 2008).

Desde otro ángulo, Silke Helfrich (2008) considera que los comunes pueden ser sistemas sociales (tangibles o intangibles) o ecosistemas interconectados distintos entre sí, pero comunes al ser heredados colectivamente, con lo cual la conceptualización sobre los comunes puede trazar diversos mapas. Cabe notar, como lo señala Bollier (2011) que no puede haber un inventario de comunes: the commons surgen cuando una comunidad dada decide que desea manejar un recurso de manera colectiva y se privilegia el acceso y uso equitativos y su sustentabilidad. Para las reflexiones que se proponen en este texto, interesa no solamente visibilizar el extendido panorama que abarcan los comunes, sino destacar las formas en las que la participación asociativa podría ser constituyente, apropiadora y generadora de bienes comunes, ya que, como se ha argumentado, para la existencia y preservación de los comunes es necesario que existan agrupaciones comunalizadoras (Bollier y Helfrich, 2012) que decidan la gestión y uso de sus recursos de manera colectiva.

Los cambios en la visión sobre los comunes conducen también a una nueva noción sobre lo que es común que se amplía desde el naturalismo y el economicismo hacia los ángulos sociopolíticos de una actividad común (David 
y Le Dévédec, 2016). Es decir, se considera lo común no solamente como pertenencia o copropiedad, sino como principio político que abarca movimientos y corrientes de pensamiento que integran la acción ciudadana para resistir al capital, limitar la extensión de la propiedad privada a todas las esferas de la sociedad, de la cultura y de la vida, y evitar la tragedia de lo no común.

\section{Bienes comunes y asociaciones}

El estudio de la conceptualización de los bienes en la esfera asociativa es aún incipiente y no se cuenta con una teoría explicativa completa, tampoco con resultados de aplicación empírica. Sin embargo, como se mencionó antes, existen numerosas referencias que reconocen diversos aspectos de las interacciones asociativas dentro del espectro de los comunes.

Dentro de esa corriente, Lohmann (1992) considera que las organizaciones no lucrativas y las asociaciones pueden ser conceptualizadas y examinadas como entidades insertas en una categoría mayor, la de los bienes comunes. Al estudiar el sector no lucrativo o voluntario, propone las formas en que diversas y dispares asociaciones disponen, producen o construyen recursos para compartir, independientemente de su naturaleza o de su complejidad, pues tejen sus relaciones sobre bases similares que incluyen, por ejemplo, la libre participación y la reciprocidad entre sus miembros.

Desde esos ángulos, el autor estableció un marco teórico para definir y clasificar a las asociaciones, comprender sus estructuras, sus reglas institucionales, sus arreglos y fines, así como los procesos sociales, económicos y políticos que estimulan o desincentivan el crecimiento de las asociaciones y coadyuvan a la acción colectiva. Lohmann consideró que es posible percibir a las asociaciones como repositorios o entidades productoras de bienes, también como agregacio- 
nes de esfuerzos para resolver problemas (Lohmann, 1992). Podría decirse que el objetivo de la asociación y la pertenencia a ella, sustancialmente, se convierten en sinónimo de identidad para los grupos asociativos y para sus miembros y, de ese modo, se construyen como ámbitos y sentidos de carácter colectivo.

Por su parte, Mark Warren (2001) sostiene que los bienes que las asociaciones buscan generar tienen impactos democráticos que derivan de su participación en la vida pública. Además, considera que es a través de las asociaciones que la gente organiza sus intereses, valores y opiniones y actúa sobre ellos. Para Warren (2001), los propósitos de las asociaciones son bienes constitutivos, como un conjunto de elementos que marcan una tendencia intrínseca y definen su misión en términos de un bien dominante. El autor argumenta que la mayoría de las asociaciones pueden ser caracterizadas en términos de sus bienes constitutivos e identifica algunos tipos: 1) bienes individuales o bienes sociales; 2) bienes que en función de sus características son excluyentes y no excluyentes; 3) bienes materiales o simbólicos; y 4) bienes escasos y abundantes. ${ }^{10}$

10. La combinación entre estas distinciones produce otras clases de bienes que pueden aportar a la clasificación de las asociaciones. Warren (200l) establece una representación de los impactos democratizadores de los bienes asociativos distinguiendo tres clases: I) la primera clase, que tiene que ver con el desarrollo a nivel individual, en la que se ubican bienes como la identidad interpersonal, eficacia e información, habilidades políticas, habilidades deliberativas y virtudes cívicas; 2 ) la segunda clase, que se refiere a los resultados en la esfera pública, en la cual se ubican la deliberación política, la representación de comunidades y la representación de las diferencias; y 3) la tercera clase, correspondiente a los efectos institucionales, en que el autor considera bienes como la coordinación, cooperación, resistencia, representación y legitimación. Como el propio Warren deja claro, eso no significa que todas las asociaciones posean todas 0 algunas de esas facetas, ya que existen muchas que no solamente no cumplen con esas expectativas, sino que incluso infringen daño a esas intencionalidades, pero el autor también deja claro que quienes se unen a las asociaciones tienen ganancias y ventajas de capital social que no son accesibles a quienes se mantienen alejados de ellas, ventajas que son estimadas como recursos comunes. 
Derivado de su análisis, Warren (2001) establece tipos de asociaciones que cuentan con derechos adquiridos sobre cierto tipo de bienes, por ejemplo, clubes recreativos, asociaciones deportivas, grupos culturales, clubes de élite, grupos nacionalistas o patrióticos, asociaciones religiosas, partidos políticos, organizaciones educativas, empresas, asociaciones civiles, fundaciones, etc. Aun cuando es claro que los propósitos de Warren al examinar los bienes son diferentes a los que se discuten en este texto, y que su análisis se centra en el asociacionismo de los Estados Unidos, se estima que algunos de sus hallazgos pueden ser aplicados e interpretados en el sentido de ver como bienes comunes a la acción asociativa y los recursos que se generan en las asociaciones.

\section{Los bienes asociativos}

Una vez discutida la posibilidad de ampliar la visión sobre los bienes que se generan e intercambian en el entorno asociativo, es necesario proceder a la identificación de los recursos y bienes de las asociaciones y preguntarse, en tal caso, cuáles son y si es posible considerarlos como comunes.

Para responder, proponemos distinguir dos ámbitos: la relación miembro-asociación y la relación asociación-sociedad. El primer ámbito comprende la pertenencia o membresía de individuos a las asociaciones que los integran como usuarios del conjunto de recursos con que cuentan mediante relaciones que derivan en posibilidades de accesibilidad, de exclusión y de apropiación de un conjunto de bienes compartidos. El segundo ámbito se particulariza en la participación e integración de las asociaciones en la sociedad, con lo cual tanto las asociaciones como la sociedad en general se configuran como productoras y usuarias de un ámbito compartido de lo que se considera lo común. Habría que notar que los bienes generados por las asociaciones en ese campo son de carácter cuasicolectivo (Nyssens y Petrella, 2015), 
carácter que comprende bienes y servicios como el cuidado de niños y ancianos, los servicios de integración social, el financiamiento social y otros, que benefician no solamente a sus usuarios y proveedores, sino a la colectividad.

Con esas distinciones, se intenta entender, primero, por bienes asociativos a aquellos a los cuales acceden los miembros de las asociaciones como resultado de su participación en ellas, y que comparten como miembros/usuarios con el resto de los integrantes; segundo, por bienes comunes, a aquellos que se generan como resultado de la acción colectiva orientada hacia los fines de las asociaciones, mismos que la sociedad puede usar y compartir en la búsqueda del bienestar y de mejorar la calidad de vida. Ahora bien, para regular el acceso a los bienes, al igual que otras instituciones de acción colectiva, las asociaciones establecen reglas que pueden ser articuladas como derechos de acceso, apropiación, gestión, administración y transferencia.

Respecto a este punto, cabe reflexionar que los recursos internos de las asociaciones pueden considerarse como bienes de acceso limitado, y que los bienes vinculados con el entorno son de acceso abierto, pues los ciudadanos pueden acceder a ellos y usarlos sin necesariamente formar parte de una asociación o tener que pagar o dar a cambio algo por ellos. Asimismo, estos bienes no están regulados de manera formal; por ello, beneficios como el expertise y el conocimiento han sido ubicados como comunes. ${ }^{11}$ Así, el conocimiento cívico refiere al conocimiento que la gente crea, usa y preserva cuando actúa como miembro de la sociedad civil; en las redes de la sociedad civil descansa la responsabilidad de crear esas condiciones (Levine, 2011).

II. Desde otro punto de vista, se contempla la acción colectiva cruzada por las ideas y el conocimiento y que se mueve a través de grupos y personas, articulada por redes de información que han sido identificadas como comunidades virtuales, o culturales. Las redes crean espacios compartidos de aprendizaje, información e interacción que inciden en la conducta de sus miembros y que son a su vez transformados y ampliados por ellos (Beagle, 2006). 
Para profundizar estas reflexiones, se propone una clasificación en la cual ubicar recursos tangibles e intangibles, tanto al interior de las propias asociaciones como fuera de ellas, es decir, en su entorno compuesto de actores de diversos sectores (público, privado o social). Esta clasificación se sintetiza en la Figura 1.

Figura 1. Bienes resultados de las interacciones asociativas

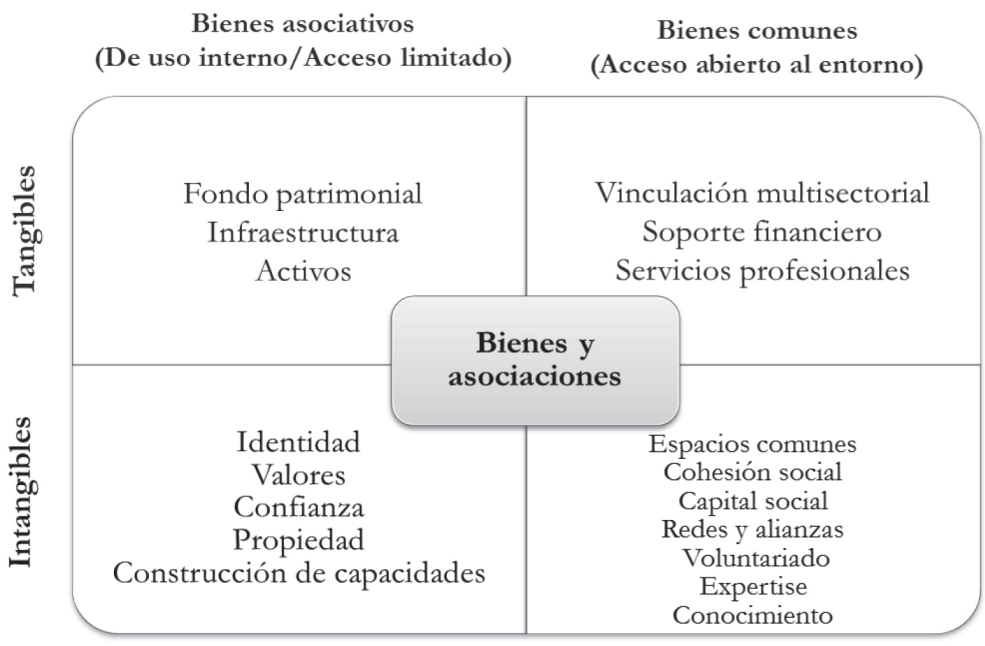

Fuente: elaboración propia.

Como se puede observar, en los reservorios de recursos internos (common-pool resources) se ubican aquellos que tienen que ver con la construcción de capacidades tanto en el plano individual como de las propias asociaciones, y estos pueden ser tangibles e intangibles. En cuanto a los recursos tangibles/materiales, se identifican: 1) fondo patrimonial, que fomenta la visión a largo plazo y la sustentabilidad de un patrimonio; y 2) activos e infraestructuras, que brindan acceso a activos compartidos (oficinas, equipos de cómputo, 
certificaciones, bienes económicos, servicios, etc.) o bienes con algún tipo de valor cuantificable.

Asimismo, en las asociaciones se generan recursos intangibles/simbólicos, como: 1) identidad, pues la mayoría de sus miembros se conocen entre sí y participan en función del conjunto de rasgos propios de la asociación; 2) fomento de valores humanos y sociales entre sus miembros y, a su vez, búsqueda de promoverlos en su entorno; 3) confianza, pues construyen actitudes, valores, reglas, articulan y coordinan las expectativas generadas por la asociación y, con ello, aumentan las posibilidades de fomentar la cooperación; 4) propiedad, es decir, derechos compartidos por los miembros y capacidades de decidir sobre el acceso, reglas de uso y conservación de recursos; y 5) construcción de capacidades como liderazgos sociales con conciencia cívica, esto mediante el involucramiento de personas que pertenecen a diversos sectores y con distintas experiencias como miembros de la asociación (dentro de un consejo de socios o de equipos operativos), y como miembros de otras organizaciones.

Dentro de los bienes tangibles/materiales que las asociaciones comparten con el entorno, se pueden incluir los siguientes: 1) vinculación multisectorial, esto es, de representantes de diferentes sectores con la comunidad local, porque estos buscan sensibilizar e informar sobre problemáticas y necesidades específicas para posteriormente incorporarlas en agendas de trabajo; 2) soporte financiero, dado que, por su propia naturaleza, las asociaciones buscan capturar, distribuir y redistribuir diversos recursos destinados a sus propósitos o sustento; y 3) servicios profesionales, pues brindan servicios de capacitación, consultoría o evaluación a otras organizaciones sociales, instancias públicas e iniciativa privada.

Otros recursos compartidos con el entorno son de tipo intangible, considerando los siguientes: 
1. Espacios comunes, en los cuales es posible la libre participación (dos ejemplos son los espacios de convocatoria para diversos actores de la sociedad y los espacios de diálogo para quienes deseen participar);

2. Cohesión social, pues las asociaciones promueven la disolución de conflictos sociales, fomentan la interacción e integración social y promueven valores;

3. Capital social, es decir, las asociaciones, en colaboración con otros actores, generan capital social entre sus miembros y entre sus beneficiarios, esto mediante la creación de redes con otros actores sociales a través de las cuales se intercambian información y apoyo y se fomenta la cohesión social (Soloaga, 2010). El capital social se considera también un capital cívico, ya que se constituye en torno a beneficios de carácter colectivo y puede activar lazos sociales democráticos, pensando al capital social como el factor organizador de la productividad asociativa (Laville, 2015, p. 150);

4. Redes y alianzas construidas con otras organizaciones locales e internacionales;

5. Voluntariado, pues aprovechan el apoyo social ofertado, voluntariamente, por ciudadanos activos de la comunidad local;

6. Expertise, ya que desarrollan conocimiento sobre su sector y especialidad, además de que optimizan la experiencia de actores del sector académico, público y social;

7. Conocimiento, pues amplían el conocimiento, el pensamiento y el saber derivado de la formación individual y colectiva de sus miembros y de la propia asociación, el cual puede ser transmisible y acumulable.

Después de esta breve exposición, es pertinente aclarar, por un lado, que el proceso de generación, acceso y uso de bienes implica que no necesariamente todos los tipos de bienes son generados por todas las asociaciones y que, 
obviamente, no todas obtienen los resultados marcados por sus metas comunes, y, aún más, que sus resultados no siempre responden al interés público.

Por otro lado, su intervención se enmarca en acuerdos de operación coordinada y esquemas normativos que propician la gestión de recursos comunes, pero también en el compromiso de las asociaciones, expresado en la aceptación de mecanismos de cooperación. Se puede decir que desde corrientes de pensamiento muy diferentes sobre la economía, las motivaciones y las formas de participación asociativa, habría un punto de convergencia en considerar que las asociaciones son ámbitos de generación de comunes.

\section{Conclusiones}

Los presupuestos teóricos examinados sobre la naturaleza de los bienes asociativos son herramientas analíticas que se constituyen sobre la plataforma de diversas propuestas interesadas en el estudio de la construcción de proyectos sociales que permiten anticipar una economía basada en el respeto a la necesidad de la permanente recreación de comunes (Helfrich, 2008). Ostrom (2014), Hess (2008), Lohmann (1992) y Bollier y Helfrich (2012) coinciden en destacar de los ciudadanos sus formas creativas de construir instituciones para producir, usar, manejar, ampliar y compartir recursos en entornos complejos. En este tenor, las asociaciones pueden verse como actores sociales con capacidad de negociación con otras organizaciones, instituciones e individuos, y también como espacios de intermediación entre diferentes esferas.

Basados en el argumento anterior, podemos mencionar algunas ventajas sobre la pertinencia de aplicar la noción de comunes al estudio de las dinámicas asociativas. Una ventaja es su amplitud, pues la noción considera un sinnúmero de bienes y resultados de acción colectiva (ya sean 
generados o que puedan sostenerse a largo plazo), así como comprende la diversidad de comunidades, de mecanismos e instituciones de manejo de recursos colectivos y la diversidad de las asociaciones y otros espacios de actuación.

Otra ventaja del enfoque es que reconoce como actores centrales a los ciudadanos (poseedores de derechos y de responsabilidades), conscientes del valor que poseen los comunes para nuestra calidad de vida.

Una ventaja más es que permite ver a las asociaciones como entidades económicas solidarias, ángulo desde el cual se les percibe como actores esenciales en los desenvolvimientos recientes de la economía que abren espacio a nuevas formas organizacionales que brindan servicios y bienes que el Estado y el mercado no pueden proporcionar y otorgan diferentes valores a las prácticas de reciprocidad y solidaridad que las asociaciones ponen en juego.

La noción de bienes comunes aplicada a los bienes asociativos es también pertinente porque permite particularizar las potencialidades de las asociaciones para ampliar el acceso a recursos compartidos y enfrentar los desafíos que impone la economía de mercado y, en ese sentido, construirse como comunalizadoras que preservan y crean nuevos comunes.

Por otra parte, la concepción de lo privado-social aporta una mirada diferente a la medición o estimación cuantitativa de sus intervenciones, que destaca los aspectos intangibles de los esfuerzos cooperativos de las asociaciones, no sólo en el sentido de costo-beneficio, sino en términos de una economía colaborativa (Donati, 1999). La acción colaborativa está implícita, por ejemplo, en el hecho de que muchas asociaciones han podido sustituir el acceso a recursos por el acceso a ciertos medios para adquirir otros recursos.

No obstante, resulta imperativo reconocer que el enfoque también enfrenta obstáculos para aplicarlo a entornos distintos a los recursos naturales, universo en el que ya 
ha sido posible integrar una visión conceptual y empírica. Primeramente, más que un problema de traducción del término commons, aún existen ambigüedades en el uso del concepto, porque no hay consenso sobre su significado y aplicación. Adicionalmente, las asociaciones han sido tradicionalmente percibidas como unión de actores privados, lo que obstaculiza percibirlas como ámbitos de acción colectiva. Asimismo, prevalece la imagen de las asociaciones como campos de conflicto de intereses en los cuales es imposible que existan consensos, reglas, valores comunes o confianza. Finalmente, es necesario señalar que persisten obstáculos sobre cómo aprehender y cómo dar cuenta de algunos de los resultados y los beneficios que generan las asociaciones, particularmente respecto a estimar en términos económicos el valor social de los bienes generados.

En todos estos señalamientos críticos, queda claro que la extensión de la noción de los comunes a los bienes asociativos es todavía un enfoque en construcción que requiere de nuevos modelos y categorías conceptuales que aporten mayor claridad y consistencia a los estudios sobre las dinámicas asociativas.

La discusión sobre los obstáculos y las ventajas en torno a los bienes asociativos resulta importante en el análisis de los problemas que afectan el desarrollo en un mundo conflictivo, donde la sociedad civil realiza una lucha permanente por preservar su autonomía, buscando mantener formas organizacionales que le permitan decidir sobre asuntos propios como el uso y disposición de sus recursos comunes. En ese marco, nuevas vías para conceptualizar los beneficios generados por la participación de ciudadanos pueden contribuir a construir formas de gobernanza democráticas e incluyentes. $€$ 
Alexander,J. (2006). The Civil Sphere. Nueva York: Oxford UniBibliografía versity Press. doi: 10.1093/acprof:oso/9780195162509. 001.0001

Aligica, P. D. (2016). "Neither market, nor state domain: Nonprofits from the Ostroms' theoretical perspective". Nonprofit and Voluntary Sector Quarterly, 45(45), 43-60.

Argandoña, A. (1998). "The Stakeholder Theory and the Common Good”.Journal of Busines, I 7(9-10), I093-I 102. doi: I0.1023/A: I0060755 I7423

Beagle, D. R. (2006). The information commons handbook. Nueva York: Neal-Schuman, Publishers, Inc.

Bollier, D. (20I I). "The commons, short and sweet". News and perspectives on the commons. Recuperado de: http:// www.bollier.org/commons-short-and-sweet

y Helfrich, S. (2012). "Introduction", en D. Bollier, y S. Helfrich (eds.), The wealth of the commons. A world beyond market \& state [version en línea] (s/p). Massachusetts: Levellers Press. Recuperado de: http://www. wealthofthecommons.org/contents

Chanial, P., y Laville,J.(20I3).“Asociativismo”, en A. D. Cattani, J. Coraggio, y J. Laville (eds.), Diccionario de la otra economía (pp. 36-42). Buenos Aires: Universidad Nacional de General Sarmiento. Recuperado de: http://www. jeanlouislaville.fr/es/diccionario-de-la-otra-economia/

Coriat, B. (dir.) (2015). Le retour des communs : La crise de l'idéologie propriétaire. París: Éditions Les liens qui Libèrent.

David, P. M., y Le Dévédec, N. (20I6). "Des communs au commun: Un nouvel horizon sociologique”. SociologieS, s/p. Recuperado de : http://sociologies.revues.org/5652

Donati, P. (1999). La ciudadanía societaria. Granada: Universidad de Granada.

Edwards, M. (2008). Just another emperor. The myths and realities of philanthrocapitalism. Nueva York: Demos: A Network for Ideas \& Action and the Young Foundation. 
Bibliografía
(20II). "Introduction: Civil society and the geometry of human relations" en M. Edwards (ed.), The Oxford handbook of civil society (pp. 3-14). Nueva York: Oxford University Press. doi: 10.1093/oxfor$\mathrm{dhb} / 9780195398571.001 .0001$

Esping Andersen, G. (1990). The three worlds of welfare capitalism. Nueva Jersey: Princeton University Press.

(1999). The social foundations of postindustrial economies. Nueva York: Oxford University Press. doi: 10.109 3/0198742002.001.000I

Estivill, J. (20I5). "Prólogo: el asociacionismo vector de la economía solidaria”, en J. Laville (aut.), Asociarse para el bien común. Tercer sector, economía social y economía solidaria (pp. 7-25). Barcelona: Icaria-Antrazyt.

Grouiez, P. (20I5). "Le retour des communs”. Revue de la Régulation, I $8\left(2^{\circ}\right.$ semestre), I - 18. Recuperado de: https:// regulation.revues.org/ I 1549\#text

Gutwirth, S., y Stengers, I. (2016). "Le droit a l'epreuve des commons". Revue Juridique de l'Environnement, 2016(2), 306-343. Recuperado de: https://works.bepress.com/ serge_gutwirth/I19/

Hardin, G.(1968). “TheTragedy of the Commons”. Science Journal, I62(3859), I243-1248. doi: I0.1080/I9390450903037302. Hardt, M., y Negri, A. (2009). Commonwealth. Massachusetts: Harvard University Press.

Helfrich, S. (2008). "Commons: ámbitos o bienes comunes, procomún o lo nuestro”, en S. Helfrich (comp.), Genes, bytes y emisiones: bienes comunes y ciudadanía (pp. 42-48). México: Fundación Heinrich Böll.

Hess, C. (2008). "Mapping the New Commons, in Governing Shared Resources: Connecting Local Experience to Global Challenges" (documento presentado en la 12th Biennial Conference of the International Association for the Study the Commons). University of Gloucestershire, 
Cheltenham, Inglaterra. Recuperado de: http://surface. syr.edu/cgi/viewcontent.cgi?article $=1023 \&$ context $=$ sul Laville, J. (20I5). Asociarse para el bien común. Tercer sector, economía social y economía solidaria. Barcelona: Icaria Editorial.

Young, D. R., y Eynaud, P. (20I5).“Introduction”, en J. Laville, D. R.Young, y P. Eynaud (eds.), Civil society, the third sector and social enterprise. Governance and democracy (pp. I-29). Nueva York: Routledge.

Levine, P. (20I I). “Civic knowledge”, en M. Edwards (ed.), The Oxford handbook of civil society (pp. 362-374). Nueva York: Oxford University Press.

Lohmann, R. (1992). The Commons: New Perspectives on Nonprofit Organizations, Voluntary Action and Philanthropy. Estados Unidos: Indiana University.

Nonini, D. M. (2006). "Introduction: The global idea of "the commons"'. Social Analysis, 50(5), I64- I77.

Nyssens, M., y Petrella, F. (20I5). "The social and solidarity economy and Ostrom's approach to common pool resources. Towards a better understanding of institutional diversity", en J. Laville, D. R. Young, y P. Eynaud (eds.), Civil society, the third sector and social enterprise. Governance and democracy (pp. 178-190). Nueva York: Routledge.

Orsi, F. (20/3). "Elinor Ostrom et les faisceaux de droits: L'ouverture d'un nouvel espace pour penser la propriété commune". Revue de la régulation, 14, s/p. Recuperado de: http://regulation.revues.org//047|

Ostrom, E. (1992). Governing the commons: The evolution of institutions for collective action. Londres: Cambridge University Press.

(20I4). "Más allá de los mercados y los Estados: gobernanza policéntrica de sistemas económicos complejos. Conferencia de recepción del premio Nobel de Economía (2009, diciembre)". Revista Mexicana de Sociología, 76(especial), 15-70. 
Bibliografía

Soloaga, I. (coord.) (20I0). Evaluación externa 20I0: efectos del Programa de Coinversión Social en la construcción del capital social. México: COLMEX, SEDESOL INDESOL. Recuperado de: https://www.gob.mx/cms/uploads/attachment/ file/216121/Informe_Final_Eval_Capital_Social.pdf

Walzer, M. (1991)."The idea of civil society:A path to social reconstruction”. Dissen, 39, 293-304.

Warren, M. (200I). Democracy in Association. Political Theory Series. Princeton, New Jersey: Princeton University Press. (2009). "Civil society and democracy", en M. Edwards (ed.), The Oxford handbook of civil society (pp. 377-390). Nueva York: Oxford University Press. 